\begin{tabular}{|c|}
\hline ASHS Presidential Address: \\
Where to Grow from Here? \\
Curt R. Rom1 \\
President of ASHS, 2015-2016 \\
Associate Dean for International Education University Professor of Horticulture University of \\
Arkansas, Fayetteville, AK, August 2016
\end{tabular}

Colleagues, friends, and esteemed guests, it is a pleasure to be here and share some thoughts with you.

As a year of serving on the American Society for Horticultural Science (ASHS) Board of Directors concludes this week, two words immediately come to my mind. Thank You.

I extend my thanks to the members of the ASHS, my peers, colleagues and friends for allowing me to serve the society, my society, as its executive officer. Service on the Board has broadened my knowledge of horticulture across the United States, what our academic institutions, federal and state agencies, and public and private companies are doing to contribute to the food system, to the environment, to the needs and quality of life of people by producing horticultural products and services. Although familiar from a $35+$ year as a professional horticulturist and after growing up on a fruit farm and son of a professional academic horticulturist, I have deepened my appreciation for our discipline. Thank you for that opportunity not only to serve but also to learn.

My thanks are extended to all who serve the ASHS in various capacities. The ASHS is a volunteer-directed and led organization. More than 300 ASHS members, a significant portion of active full-time members, serve the Society in some capacity of leadership, or on a Society committee. Without volunteers serving each other, the Society would not function.

Lastly, my thanks are given to all who, at this conference, are participating by presenting papers of their discoveries, innovations, technologies, and experiences. More than 700 abstracts have been submitted for scientific sessions, workshops, posters, or other opportunities to share and engage with others of horticultural interest. It is this information exchange and networking that makes the ASHS annual conference enriching, engaging and enjoyable.

As horticulturists, we grow gardens - in reality, virtually, and metaphorically. The ASHS is garden in which we like to work. This garden creates opportunities.

As President, I had the opportunity to sit with a group of graduate students for an information exchange session. Their ideas and

\footnotetext{
${ }^{1}$ Dr. Rom delivered his Presidential Address on 11 Aug. 2016, during the 113th ASHS Annual Conference, which was held in Atlanta, GA.
}

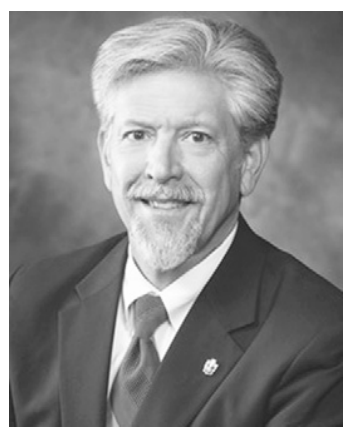

input were being sought as to how to improve the ASHS and to better serve graduate students and developing professionals. A wide array of topics surfaced that transitioned into a discussion on career planning and professional development.

At a point in the discussion, Lily, a graduate student attending her first ASHS conference asked me, "How did you get to where you are; how did you become a professor and then President of the ASHS?" This was an important and poignant question, and it caused me to think.

Reflecting upon this past year as President, and my previous years as a horticulturist and member of ASHS, I know recognize that there has been many who have help lead me, guide me, nurture me, challenge me, encourage me and support me in my career as a horticulturist. Along my way, I had many wonderful teachers including Joe McFerran, who taught me Principals of Horticulture, and Gerald Klingaman, who taught me plant materials, nursery management, and plant propagation. My own father, Roy Rom, was the instructor for my tree fruits class. In graduate school, I was encouraged by Fred Hartman, Garth Cahoon, Dale Kretchman, and Carroll Swanson. I had inspiring instructors such as John Peterson and Dan Lineberger. The all helped me to learn and demonstrated how to teach and share a passion for plants and horticulture.

I was encouraged in research by Jim Moore, who hired me as an undergraduate student, and my graduate mentor David Ferree. There were many important colleagues in my professional development such as Wayne Loescher, Virginia Lohr, and Robert Kennedy. I was hired, supported, and encouraged by department heads such as Paul Rasmussen, George Bradley, and Wayne MacKay.

My colleagues were a source of encouragement and inspiration. As an undergraduate I met several students who have had distinguished horticulture careers such as Randy Woodson. I worked with graduate students such as Carlos Fear, Tim Bourne, Judy Caldwell, Ed Hellman, and Bruce Bordelon - they helped stimulate my interest in horticulture research and the profession. In graduate school, many peers such as Stephen Myers, Rebecca Darnell, John Kelly, Mary Albrecht, and many others made learning and discovery fun and engaging. I have had great horticultural colleagues such as John Clark, Esmaeil Fallahi and Peter Hirst who have become trusted friends.

A group with the largest influence in my professional career has been my students. Over the past 32 years, I have taught courses at The Ohio State, Washington State University, and University of Arkansas and have encountered 1000s of students in class, and through student activities. The students made me prepare for class and learn my subject matter. They challenged me and they thanked me. Many worked for me just as I started my horticulture career working for a professor. With many, I still maintain contact. I had the fortune to have completed 21 graduate students and many are colleagues such as Elena Garcia, Renae Moran. I have participated on more than 50 other graduate committees and several of those graduates are now my peers in ASHS. Next to being around plants, I think being around students is the most wonderful and rewarding aspect of being an academic horticulturist.

A special group with whom I worked were the program technicians that helped manage and operate studies and experiments in my lab, the greenhouse, and the field. They were challenged to bring to fruition many ideas, and to keep things moving when my daily routine would be interrupted with classes, students, and meetings. They kept things growing. They filled-in the gaps and helped supervise and mentor students. My technical staff significantly contributed to my success, especially Matt Stasiak, Andy Allen, Jason McAfee, and Heather Friedrich. They were dedicated, loyal, and helpful; they were as curious about learning as I was. They were my friends and peers; we were a team. 
My involvement in ASHS was guided by my mentors and peers. I have had several department heads and peers, who contrary to the current common wisdom, encouraged me early in my career to be involved, be engaged, and to participate in the leadership of the Southern Region, and the ASHS. Every step of the way, I was mentored, encouraged, and supported. The best part of the ASHS network was the free and open exchange of ideas and the strong professional friendships that were developed.

Therefore, this comment is for Lily. I did not get to this stage of my career, to have success, and the position of President of ASHS by myself. It was with the help, encouragement, direction, and nurturing support of many, many people. To them, I will be eternally grateful. Because of them, I am proud to be a horticulturist. I owe so many people so much thanks for cultivating me. Thank you.

\section{State of the Society}

In reviewing previous presidential addresses, several common themes were observed. Those themes included defining horticulture-what is it and how does it contribute, defining the challenges, assessing the external pressures affecting horticulture and the profession, understanding the internal pressures facing the profession, the science, academics, and outreach, expressing deep concerns about the future of the profession and Society as it was evolving, and stating incredible optimism for the future of the profession and the Society as it contributes so importantly not only to science, but also to the economy, to society, to the environment, to our communities and to the well-being of individuals. After my terms on the Board spanning two decades, and my recent service as President, this address will likely contain elements of them all.

As the ASHS continues to ever move forward, develop and evolve, it is important that we remember the objectives, purpose, and structure of the ASHS. In the articles of the constitution it states, "The object of the Society shall be to promote the Science of Horticulture." The word "promote" in this context can be interpreted several ways. Promote may mean to publicize and advocate for the science of horticulture. It may also mean to advance, move forward, and expand the knowledge base of horticulture. Just as that objective was drafted in 1903, it is still relevant today. The founding members of the Society drafted a simple phrase that is still very relevant to the Society's mission today.

The development of new science, information, technology, and innovation is what we each do individually in our research, outreach, or teaching careers. Individually, however, sometimes accomplishments and progress could be lost or go unnoticed. This is the value of our Society. The ASHS lives to its primary objective, to promote horticulture science, through its tripartite mission being the primary functions of publications and communications (emails, newsletter, and website), annual conferences, meetings and advocacy, and the networks and professional associations that are forged. These are the core functions; publications, meetings, and networking. An analysis of the annual budget demonstrates that overall, those are the purposes and functions of the Society. A strong professional Society is to the collective benefit of us each as individuals. For in science, just as in an army, there is strength in numbers.

The ASHS, since its inception and continuing today, is a member driven, member benefits professional Society. In essence, without participatory membership there is no Society. The ASHS has relevance and vibrance because it is directed and led by members, by its volunteers. There is this strong link between membership, services, and accomplishment. Without members, the Society ceases to function or exist. To be a strong society, members must contribute in its tripartite mission and programs. Members must participate in the Society by publishing in its journals and contributing to its publications, and by reading and citing the works of others published in its journals. Members contribute to the promotion of science by presenting their discoveries, information, and experiences at annual conferences and through advocacy events. Members strengthen the Society community by engaging with each other in the professional networks and collaborating and cooperating with each other. In return, the Society provides a strong memberdriven framework for those activities.

The life of the Society is and has always been a topic of discussion; where are we, are we growing or will we die, are we too focused or too diverse, are we relevant? From the beginning, this was questioned. In 1904, in his Presidential Address, our progenitor, Liberty Hyde Bailey asserted, "I doubt whether the horticulturist will persist long in the highly defined (and divided) schemes of education and investigation." (1904, Proc. ASHS).

So, how are we as a Society doing? Where are we growing?

Membership is steady. The total membership is up in all categories since 2015. A membership decline that was observed in the ASHS, and many professional societies, has slowed over the past decade. There is strong growth in student memberships and a small but steady growth in new memberships as new horticulturists enter the field. These are signs of a healthy Society. However, attrition of members - those who do not continue membership from one year to the next especially among active, professional members, and graduate students - is a concern. The ASHS is taking progressive steps to help graduate students transition from student to professional, active membership. ASHS Leadership and membership committees are working to address attrition of active, professional members.

Attendance at this conference in 2016 has been the largest in a decade. The number of submitted and scheduled abstracts for the conference has increased. Several new elements have been added to the conference, suggested by members, such as plenary and general sessions, more time for networking, and increased planned social events. The next three conferences in Hawaii (2017), Washington, D.C. (2018), and Las Vegas (2019) are all scheduled for wonderful conference venues in attractive locations. The trend for strong conferences will continue. These are indications of a growing, evolving, active Society and membership.

The publications, as a core mission, continue to attract manuscripts. The year 2015 saw a record number of manuscripts and page submissions and that will likely be exceeded in 2016 if the current trend continues. The five-year impact factor has increased for all publications. As members' and users' reading and use habits have changed, subscriptions to the publications have declined. This is consistent with many if not most professional science societies. Nevertheless, with online and digital access, use may have significantly increased. In 2015, there were more than 5.6 million digital accesses of the publications and more than 2.3 million views of papers online or downloading copies. Since the Society has tracked this, more than 12 million articles have been read or downloaded. The information that Society members contribute through the ASHS publications is having an impact. The ASHS continues to promote the science of horticulture in new ways with its publications.

The Finance Committee and Board have important fiduciary duties for the financial budgeting and oversight of financial matters. These member groups develop and review the annual budget. With the strong management of the ASHS Headquarters staff, the Society stays within its budget and has had chances to put some funds into building its reserve. A goal has been to maintain the Society as a financial lean and conservative organization, and therefore affordable to its members while providing high levels of service around its core missions.

The edge of excellence that the Society has is revenues from its investments and endowment. Therefore, growing the endowment is important. The endowment funds the student travel grant program. In 2016, more than $\$ 37,000$ was awarded in student travel grants to attend the national conference providing opportunity and access to developing scholars, scientists, and horticulturists. This past year, more than 70 ASHS members have contributed more than $\$ 9000$ to the endowment fun, and I proudly report that the ASHS Board of Directors had 100\% contribution participation. Others in the Society are encouraged to contribute to the endowment, as this is a gift that keeps giving and will provide opportunity and excellence into the future.

The ASHS has a very active membership involved in all of the various components and strata of the organization. There are two active regions, the Southern Region and the Northeastern Region, that hold meetings in 
conjunction with other organizations and societies. The regional meetings are an entry point and pipeline for undergraduate and graduate students to be introduced to and participate in the ASHS. The ASHS, as an organization, helps to support the Regional Societies. Additionally, the ASHS supports sibling and related organizations such as the American Pomological Society, the Plant Growth Regulator Society, Pi Alpha Xi, and the Florida State Horticulture Society. The ASHS helps manage meetings, publications and finances for those organizations. These are services that support the membership and the general mission of the Society, promoting the science of horticulture.

As the president, I was able to represent horticultural science at the USDA/USAID Food Innovations Lab, Feed the Future, conference, at the Riley Foundation and American Association for the Advancement of Science (AAAS) agriculture science societies workshop developing a Unifying Message for increased agriculture research and education funding. Delegates from the ASHS attended and assisted with the Junior Horticulture Association, the AAAS Riley Memorial Lecture, the national Science Fair, the Council on Agriculture Science and Technology, and other agencies, boards, and organizations. ASHS members and staff visited the USDA and were advocates with the legislature on issues related to specialty crop research and education funding. This year, the USDA Specialty Crops Census and report was released with review and input from ASHS members. ASHS membership has a "seat at the table" and is the voice of horticultural sciences.

The ASHS is active and functioning with several divisions, many committees, task forces, and other groups that make the Society work. More than 350 members participate in leadership and service capacities of the Society, and more contribute to publication manuscript reviews, which demonstrates a deep level of engagement and commitment. The ASHS is a volunteer driven and operated organization; its members work to provide the programming and services. I am reminded by the spirit, engagement, and the networking of the Society that we are all in this together! President John Carew (1966, HortSci 1:6) told us, "The ASHS is a sturdy tree, well rooted by its founding horticulturists, and carefully nourished and trained during its youth by a succession of loyal and competent members of our profession."

To borrow a phrase from a US presidential candidate, I have heard it said that we should, "make horticulture great again." I disagree with the premise; horticulture as a discipline and an industry is already great. People that talk about the good old days are only one-half correct; those were old days. The Society is an ever changing, developing, evolving and growing society. Horticulture is great now.

The growth and development of the ASHS has been evolutionary, and sometimes revolutionary. For instance, in 1914, the
Society was extolling the success of its annual conference were there were 33 presented papers, 25 speakers, and 40 attendees (of the 179 paid members). President C.C. Corbett said, "I hope that all future meetings may be dominated by the same spirit of helpfulness and cooperation which has pervaded this one.....they may be successful...." (1914, Proc. 10th Meeting of ASHS). In order to energize the annual conference for a period of time, the ASHS met with the American Institute of Biology (now the AIB Sciences). A brave decision was made that the ASHS had grown to a point where it had its own critical mass for annual conferences. In the Letters to HortScience, N.C. Childers wrote, "With several hundred attendees and more than 100 papers, we are at a place where we can meet independently". The Society did and that continues today as was stated earlier about the success of this conference. In the $1990 \mathrm{~s}$, a difficult decision was made to forego campus-based meetings hosted by a local department and move to convention venues. This gave the conferences a more professional atmosphere and environment and allowed for continued program growth.

President William A. ("Tex") Frazier informed us, "We must recognize at the same time that greater complexity of organization is necessary to meet the explosion of knowledge and specialization." (1967. Presidential Address. Proc. ASHS). Bold decisions were proposed by the membership and annual conference evolved again when in the 1980s, Working Groups were formed to better facilitate discipline-oriented networking and focused discussion.

The Society publications have evolved as well. Since the beginning of the Society, Proceedings of the Annual Meeting were published presenting the papers from the meeting. There were step-changes ahead. With an expanding membership and expanding research programs, new technologies and instruments, and new science, the Society decided to add HortScience in 1966 as a periodical journal to replicate Science but for horticulture. In 1969, the Proceedings were discontinued entirely and another periodical was added, the Journal of American Society for Horticultural Science (Journal), and in a few short years we will celebrate its 50th anniversary. Over the years, those two periodicals have changed in format and content. In 1991, the Society added HortTechnology as a more technology and information based periodical to reach a broad user audience. In 2015-16, as many pages of papers of horticultural science have been published within those three periodicals as ever before and as previously stated, their reach through electronic means is skyrocketing. In the mid-1980s, to enhance intersociety communication, the ASHS Newsletter was added. For a period during the 1980s and 1990 s, the ASHS operated the ASHS Press as an academic press. In the 1990s, the ASHS initiated a website, and included blog posts, created listservs and virtual workgroups, and posted conference papers as podcasts. This year, a new media publication format, Hor$t I M$, for instructional and educational media is being introduced to accommodate the expanding media and information of horticultural sciences. All of these efforts live to the core mission of promoting the science of horticulture.

Promoting horticulture has become more than just printing science publications. There was need to promote and support the science in the "seat of power"- Washington, D.C. For a period, the ASHS funded a legislative Fellow from its membership. A few years back, the Board, at the suggestion and request of membership, created the National Initiatives Committee and task force, and contract the services of a professional legislative consultant. The Society became actively engaged with other plant science societies in the legislative process and had a voice in the discussions for farm bills leading to programs such as the Specialty Crops Research Initiative. These are direct membership services and indirect benefits by maintaining and working to increase funding to support horticulture science research. The ASHS has become the source of Science for Specialty Crops.

There is continued room for self-examination to prepare for new growth. Several times in the past three decades, the ASHS has gone through strategic planning processes. There were initiatives in 1990-93, 2000-03, and now a process initiated by the Board spanning 2015 and to be concluded in 2017 or 2018. In each case, the planning process was built from the ground up by membership engagement through surveys and memberdriven task forces.

The current strategic planning process is underway. A preliminary membership and constituent survey was conducted in November through December of this past year, 2015. Using membership, past membership, attendance, and other contact lists, approximately 4000 individuals were invited to participate in the first steps of planning through an electronic, web-based survey. Of those contacted, 467 completed the survey with $>11 \%$ response rate, and being $23 \%$ of the active membership. Responses were received from 49 states, 3 US territories, and 26 other countries from Europe, Asia, the Pacific region, and Latin and South America. Of the respondents, $90 \%$ self-reported they had been members and more than $80 \%$ were currently members. Of that group, more than $50 \%$ respondents had been members 11 or more years, or were late in their career and considering retirement. More than $65 \%$ of the responses reported ages of 45 years or older. Approximately $60 \%$ of the respondents worked at public land grant universities, $10 \%$ from governmental agencies, and $10 \%$ from industries or companies. Approximately $60 \%$ of the respondents indicated their primary work responsibility was research, followed by $20 \%$ extension, and $10 \%$ teaching. In ranked order, responses came from individuals who said their primary 
crop interest was fruits, vegetables, green industries, floriculture, and public horticulture. The primary reported disciplines in ranked order were crop management and physiology, breeding and genetics, molecular biology and biotechnology, plant nutrition, and plant propagation. By frequency of response, the work priorities of respondents were local and state needs, national needs, regional needs, and global/international needs.

When asked why persons had joined they ASHS, responses by frequency were, access to information, professional networking opportunities to increase a professional profile, and to publish in ASHS journal. More than $85 \%$ of the survey respondents indicated publishing in ASHS journals was important or very important to them, and similarly opportunities for publication and career awards were important or very important.

The annual conference was perceived as an important service and membership benefit. Of the respondents, $75 \%$ stated an annual conference was important or very important, and $70 \%$ said the conferences had high quality or excellent quality programming. Reasons for attending conference in ranked order of response frequency were opportunities to present professional work, opportunities for professional development, ability to gain technical knowledge, opportunities for interacting with professional peers, and networking. Of the respondents, $55 \%$ had attended six or fewer conferences, and $50 \%$ stated that they do not regularly attend the annual conference. Of the respondents, more than $90 \%$ indicated that they had volunteered for the ASHS in some capacity.

Publications were important to the survey respondents. However, publication frequency was low. Of responses, 30\% had never published in ASHS journal, and 35\% had published only 1 to 3 papers. Of the responses, however, $63 \%$ indicated that ASHS journals were the primary publication venue for their work. The most read publications in ranked order were HortScience, HortTechnology, and the Journal. The responses that rated the quality of ASHS publications as high or excellent were $58 \%$ for HortScience, $48 \%$ for the Journal, and $45 \%$ for HortTechnology.

A primary goal of the survey was to determine the primary strengths, opportunities, aspirations, and metrics of success for the Society. These would be the platform from which a strategic vision for the Society would build its future.

By frequency of response, it was indicated that the primary strengths were publications, the annual conference and workshops, networking opportunities, advocacy and promoting horticulture, the breadth and inclusiveness of disciplines and people in the Society, opportunities for professional development, student participation in activities, and working groups. These responses could be summarized, as the greatest strength is the membership, membership participation, and the diversity of the members and disciplines of the Society. This may also, as stated previously by Professor Bailey, be the greatest challenge.

The primary opportunities for the Society were to increase linkages and gain greater participation from the industry and industry partnerships, to increase public awareness of horticulture and horticultural science, to expand advocacy to support horticulture research and education, to expand the scientific presence of the ASHS and its members, to develop better outreach and engagement to students in order to foster new scientists, to strengthen and increase activity of working groups, to update and modernize the annual conference, and to improve and modernize publications including new platforms. It is clear, that the greatest opportunities are to significantly increase industry engagement, support and participation and to focus on and strengthen the core mission of the ASHS.

The primary aspirations of respondents for the Society were to make the ASHS the premiere professional science society for horticulture, specialty crops and plants sciences, to increase the prestige of the Society and its membership, to become the premier conference and meetings for specialty crops and plant sciences and improve the prestige and visibility of the conference, to increase industry support and partnerships within the Society, to become the leader for specialty crop and plant science advocacy, and to set the agenda for the grand challenges facing specialty crops, to increase international participation and engagement, and become the voice of a national specialty crop research and education agenda and funding. Primary aspirations could be summarized that the Society needs to continue to evolve and become the premier horticulture and specialty crop science society, and the professional society of choice for potential members.

Respondents reported that success in strengths, opportunities and aspirations would be noted by increases in membership, membership retention, and conference attendance, that publication use, virtually and through subscription would increase, as would citation index and impact metrics, that there would be increased membership, participation and support from direct and allied horticultural and specialty crop industries and trade groups, that there would be increased prestige of the Society and its members who would be recognized nationally and internationally for achievement, that there would be an increase in younger membership and more young persons would enter the scientific and scholastic fields of horticulture, that the working groups would become more active and effective, and there would be a growth in the endowment and funding for special programs and activities.

The more than 1500 individual comments in the survey could be summarized in two comments of the respondents;

The ASHS should, "Be the best horticulture science society" and, the Society should "Stay focused on its core purpose and mission."
So, how will we grow?

The ASHS President W.A. Taylor (1909 Presidential Address, Proc. ASHS) challenges us that, "The Future of the Society is to be what we, its members, make it." A second phase of the strategic planning process is being developed by the ASHS leadership and Board. It is planned that with additional membership input, a Phase II membership survey will occur in late 2016 or 2017 to focus in on some key action points and areas of concern to the membership. The purpose will be to further understand and focus the mission of the Society positioning it for the next decade. The outcome would be to develop a path for a sustainable organization, and to become the professional Society of choice for the next generation(s) of horticultural and plant scientists.

Early it was mentioned that even our founding parent, L.H. Bailey had doubts that the horticulturist would survive because of its diversity in crops, plants, and specialization of disciplines. Maybe there is not much new within our profession. Contrary to Dr. Bailey's concern, however, the Society of horticulturists has survived and quite well.

The ASHS, however, has some grand challenges. The Society could face a changing membership clientele and their direction. As the membership indicates that it is primarily comprised of faculty of public universities, the support for public higher education will have a profound effect on the size, health and activity of the Society. Since, membership is primarily engaged in research, funding for research from state, federal or private sources will influence the level, quantity, quality, and direction of future horticultural research. It is very likely that the foci for horticulture research may move from the public domain to the private domain in the future and the ASHS and its membership will need to adjust to that new environment. As companies would likely be very mission-focused, the idea of horticultural generalists, and the cross-fertilization of ideas needed in a horticulture and/or plant science department may diminish, and the need for specialized networks may increase. Balancing the needs for generalist and specialist horticultural science will a goal.

Some reports or indications of the millennial generation and generation- $Z$, indicate they are not joiners. They tend not to join societies and participate in a traditional academic societal manner, but may be more "virtually" connected forming electronic social networks. They may be more likely to "shop around" for information and experiences and not feel a professional tie to a specific organization, set of publications, or conferences. Their information gathering may more likely resemble a neural synaptic connection. They may enjoy more indirect virtual networks than live networks. There is also evidence, however, that these generations tend to be socially engaged and develop commitment and connections to a social good and welfare; there is a need to be agents of change. Those behaviors, patterns, and 
commitments will change how academic societies are structured and function. With new and emerging technology and forms of communication, the speed of communication and information transfer will become increasingly important in the quest to adequately promote the science of horticulture. The challenge for the future growth of the ASHS will be to adapt to the new engagement behaviors and interests of new and future horticultural scientists, specialists, and teachers.
What will we grow next?

The ASHS is our garden and it is up to us to cultivate it. Bailey reminds us that, " $A$ garden requires patient labor and attention. (Gardens) do not grow merely to satisfy ambitions or to fulfill good intentions. They thrive because someone expended effort on them. The future and success of the ASHS will be what we aspire to be, and how we take action to achieve our aspirations. This Society exists for its members and determining new needs and aspirations of members, both current and the near-future generation, will be important to its continued growth. As a membership-driven organization it is continually growing and evolving, it is experiencing some of its best days now, and even better days to come. I have confidence that the ASHS will continue to be the best horticulture science society it can be. There is now and will continue to be a need to grow horticultural science for the benefit of knowledge, economics, people, communities and the environment. 